\title{
TOXICITY OF 3-METHYLPHENANTHRENE ON JAPANESE SPIKY SEA CUCUMBER (APOSTICHOPUS JAPONICUS)
}

\author{
LIU, S. $.^{1,2,3}-$ CHE, J. ${ }^{4}-$ ZHAO, Y. M. ${ }^{1,2,3}-$ WEI, H. F. ${ }^{1,2,3^{*}}-$ LIU, C. F. ${ }^{1,2,3}$ \\ ${ }^{1}$ Liaoning Key Laboratory of Coastal Marine Environmental Science and Technology, Dalian \\ 116023, China \\ ${ }^{2}$ College of Marine Science, Technology and Environment, Dalian Ocean University, Dalian \\ 116023, China \\ ${ }^{3}$ North Key Laboratory of Marine Aquaculture, Ministry of Agriculture and Rural Affairs, \\ Dalian Ocean University, Dalian 116023, China \\ ${ }^{4}$ Dalian Xinyulong Marine Biological Seed Technology Co., Ltd., Dalian 116222, China \\ ${ }^{*}$ Corresponding author \\ e-mail:weihaifeng@dlou.edu.cn
}

(Received $4^{\text {th }}$ Mar 2021; accepted $10^{\text {th }}$ Jun 2021)

\begin{abstract}
In the Marine environment, 3-methylphenanthrene mainly comes from Marine oil spill accidents and the waste water discharge from the coastal petrochemical enterprises. In order to reveal the ecotoxicological effects of 3-methylphenanthrene pollutants on A. japonicus, it was exposed to different concentrations of the substance. The results showed, the survival rate of A. japonicus gastrula decreasing gradually with the extension of exposure time and the increase of exposure concentration; The bioaccumulation of 3-methylphenanthrene in A. japonicus increased significantly with the extension of exposure time and the increase of exposure concentration; Compared to the control group, the expression of CYP450 and p53 genes of A. japonicus was significantly inhibited in each treatment group. The above results provide the basic data for the evaluation of the biological toxicity of 3-methylphenanthrene towards A. japonicus.
\end{abstract}

Keywords: pollutants, ecotoxicological effects, survival rate, bioaccumulation, gene expression

\section{Introduction}

Petroleum hydrocarbon pollution is one of the significant factors that may harm the safety of marine ecological environment in global (Li et al., 2019). The toxicity of it is mainly caused by PAH components, which are highly toxic and commonly found in aquatic systems (Guo et al., 2017). 3-methylphenanthrene is the most representative tricyclic PAHs with high content in petroleum, but its toxicity has been reported less in the international scope (Guan et al., 2016; Liu et al., 2020). The physiological activities and metabolism of organisms living in marine environments containing 3-methylphenanthrene were altered (Xu et al., 2018).

Apostichopus japonicus covered with meat spines, which feed on algae and plankton and are widely distributed in the world's oceans. It is an important mariculture economic species in China, with functions of improving memory, delaying aging, preventing atherosclerosis and anti-tumor (Bo, 2017; Zhao et al., 2020). At present, most scholars have studied the toxic effects of microplastic fibre (Mohsen et al., 2020, 2021), heavy metals (Wang et al., 2016; Zhang et al., 2016), and organic pollutants (Luo et al., 2015; Li et al., 2016a; Khazaali et al., 2016) on their larvae and adults and the accumulation of residual pollutants in their bodies, but there has been no report on the toxicity of 
3-methylphenanthrene on A. japonicus. Therefore, it is of great significance to study the toxicity of 3-methylphenanthrene to A. japonicus in China, so as to improve the quality of $A$. japonicus and strengthen the utilization and protection of marine resources.

Marine oil spill and industrial wastewater discharge cause PAHs to invade the Marine environment and destroy the balance of Marine ecosystem. 3-methylphenanthrene is widely found in marine water environment (Honda and Suzuki, 2020). It participates in the normal physiological process of marine organisms and is closely related to its life process. This article explores the different concentration of 3-methylphenanthrene on A. japonicus gastrula survival rate, bioaccumulation of 3-methylphenanthrene at different concentrations in $A$. japonicus and effects of different concentrations of 3-methylphenanthrene on the expression of CYP450 and p53 genes in A. japonicus, to provide basic data and theoretical basis for risk assessment of marine environment and aquatic organisms.

\section{Materials and methods}

\section{Experimental materials}

The seawater for the experiment was taken from the sand-filtered seawater of Dalian Heishi jiao. A. japonicus was purchased from Dalian Pacific Marine treasure co. LTD. The body length was $(2 \pm 0.3) \mathrm{cm}$. After 2 weeks of clean sea water domestication, healthy young A. japonicus was selected for experiment.

\section{Experimental methods}

\section{Effects of 3-methylphenanthrene on early development of A. japonicus}

The experiment was carried out in a $10 \mathrm{ml}$ test tube, with the gastrula density of $2 \sim 3$ $\mathrm{a} \cdot \mathrm{mL}^{-1}$ in each test tube. The experiment used continuous micro-aeration method which was used to ensure that the dissolved oxygen in the experimental water was greater than $6 \mathrm{mg} \cdot \mathrm{L}^{-1}$. The experimental method was semi-static. During the experiment, the water was replaced every 24 hours, and the water was controlled at the temperature of 20 $21^{\circ} \mathrm{C}$, the salinity of $30 \sim 31$, and the $\mathrm{pH}$ of $8.1 \sim 8.2$. According to the preliminary experiment, set four treatment groups with 3-methylphenanthrene concentrations of 10, 50, 100 and $200 \mu \mathrm{g} \cdot \mathrm{L}^{-1}$, a blank control group and a 1\%o acetone solvent control group, each group set up three parallel experiments, and the number of survivors was observed at $24,48,72$ and $96 \mathrm{~h}$, and the survival rate was calculated.

\section{Bioaccumulation of 3-methylphenanthrene in A. japonicus}

The medial lethal concentration ( $\mathrm{LC}_{50}$ ) of 3-methylphenanthrene was $264.3 \mu \mathrm{g} \cdot \mathrm{L}^{-1}$ by $96 \mathrm{~h}$ acute toxicity test. Based on this, the concentration of 3-methylphenanthrene was set as 5, 10 and $100 \mu \mathrm{g} \cdot \mathrm{L}^{-1}$. During the experiment, the dissolved oxygen was controlled above $6 \mathrm{mg} \cdot \mathrm{L}^{-1}$, and the water temperature was $20 \sim 21^{\circ} \mathrm{C}$. Algal powder of Sargassum thunbergii was fed regularly once a day, and the feeding amount was $1.5 \%$ of the body weight. Samples were taken at the $3 \mathrm{~d}, 7 \mathrm{~d}$ and $14 \mathrm{~d}$ of the experiment and stored in a refrigerator at $-80^{\circ} \mathrm{C}$ for measurement. The freeze-dried biological samples were fully weighed and added with anhydrous sodium sulfate and deuterium, followed by a mixture of $100 \mathrm{~mL}$-hexane and acetone $(1: 1, v: v)$ for accelerated solvent extraction. The sample extraction solution passed minicolumns of anhydrous sodium sulfate, and added 
desulphuration of copper powder which treated with hydrochloric acid. Concentrate the extract to about $2.0 \mathrm{~mL}$, after purification, pre-leaching and eluent taking, concentrate the eluent to constant volume, then add $1 \mu$ internal standard. The sample gas-phase separated by DB-5ms capillary column, and mass spectrometric detection was performed by EI ionization method.

Effects of 3-methylphenanthrene on expression of CYP450 and p53 genes in A. japonicus

Filled $1 \mathrm{~L}$ glass beaker with seawater, and added reserve solution of a certain concentration of 3-methylphenanthrene. The concentration of 3-methylphenanthrene was set as 5,10 , and $100 \mu \mathrm{g} \cdot \mathrm{L}^{-1}$, each group placed 10 young $A$. japonicus. Test conditions: water temperature $(15 \pm 2){ }^{\circ} \mathrm{C}$, salinity $(30 \pm 1), \mathrm{pH}(8.0 \pm 0.5)$, intermittent oxygenation, ensure that the dissolved oxygen is greater than $4.5 \mathrm{mg} \cdot \mathrm{L}^{-1}$, avoid light. After 3, 7 and 14 days of treatment with 3-methylphenanthrene, taking one young A. japonicus of each treatment group was placed on the ice, and $A$. japonicus body fluid was extracted by pipetgun, then quickly put into the prepared liquid nitrogen in the tube and stored at $-80{ }^{\circ} \mathrm{C}$. Trizol method was used to extract the total RNA of the above samples, DNase I was used for DNA digestion, the concentration and purity of total RNA were detected by micronucleic acid protein analyzer, and the RNA integrity was detected by Agilent 2100 biological analyzer. The total RNA of the above samples were retranscribed by PrimeScript ${ }^{\mathrm{TM}} \mathrm{RT}$ reagent Kit(TaKaRa). Mx3005p ${ }^{\mathrm{TM}}$ real-time fluorescence quantitative PCR instrument and SYBR Prime-Script ${ }^{\mathrm{TM}} \mathrm{RT}$-PCR Kit II were used for real-time quantitative PCR.

\section{Data statistics and processing}

The test data were expressed as mean \pm S.D. , SPSS 22.0 statistical software was used for statistical analysis of the data, and One-Way ANOVA and Duncan's new multiple range method were used to analyze the difference of the data. Set $P<0.05$, the difference was significant.

\section{Results}

\section{The effect of 3-methylphenanthrene on the early development of A.japonicus}

The changes of survival rate of $A$. japonicus gastrula under different concentration of 3-methylphenanthrene were shown in Figure 1. Compared with the control group, the stress of 3-methylphenanthrene significantly inhibited the growth of A. japonicus gastrula, and its survival rate significantly decreased with the increase of stress time $(P<0.05)$. Under the stress of 3-methylphenanthrene for $24 \mathrm{~h}$, the survival rate of A. japonicus gastrula decreased gradually with the gradually increasing exposure concentration, and the survival rate of $A$. japonicus gastrula reached the minimum value of $79 \%$ when the stress concentration reached $200 \mu \mathrm{g} \cdot \mathrm{L}^{-1}$. Under 3-methylanthracene stress for $48 \mathrm{~h}$, the survival rate of $A$. japonicus gastrula was significantly different from the control group $(P<0.05)$, and with the gradual increase of exposure concentration, the survival rate of $A$. japonicus gastrula decreased gradually. When the stress concentration reached $200 \mu \mathrm{g} \cdot \mathrm{L}^{-1}$, the survival rate of $A$. japonicus gastrula reached the minimum value of $66 \%$. Under 3-methylanthracene stress for $72 \mathrm{~h}$, the survival rate of A. japonicus gastrula was similar to result of 3-methylanthracene stress for $48 \mathrm{~h}$, and the survival rate of A. japonicus gastrula was $0 \%$ at $200 \mu \mathrm{g} \cdot \mathrm{L}^{-1}$. Under the stress of 3-methylanthracene 
for $96 \mathrm{~h}$, the survival rate of A. japonicus gastrula reached the lowest value as a whole, and the survival rate of $A$. japonicus gastrula reached $0 \%$ at $100 \mu \mathrm{g} \cdot \mathrm{L}^{-1}$ and $200 \mu \mathrm{g} \cdot \mathrm{L}^{-1}$.

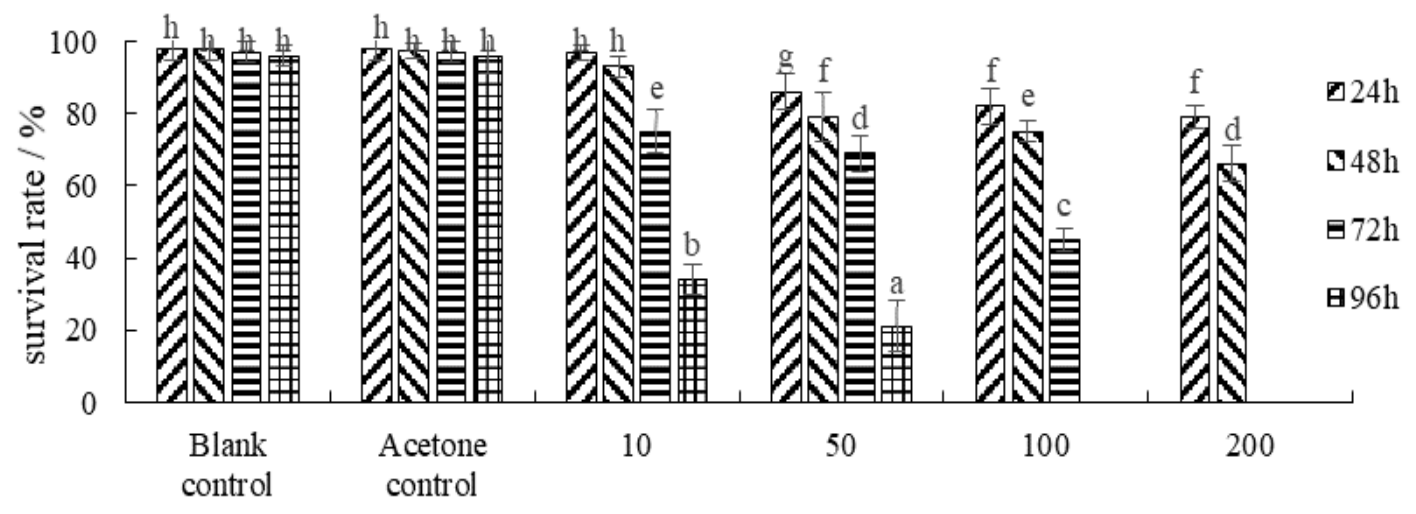

3-Melthylphenanthrene treatment group $/\left(\mu \mathrm{g} \cdot \mathrm{L}^{-1}\right)$

Figure 1. Results of acute toxicity test of 3-Melthylphenanthrene on early development of A. japonicus. Note: The means with different letters significant differences at the 0.05 probability level, and the means with the same letters not significant differences. The error line in the figure is expressed by standard deviation, which is the mean of the distance of each data from the mean

\section{Results of 3-methylanthracene bioaccumulation in A. japonicus}

Figure 2 shows that under $5 \mu \mathrm{g} \cdot \mathrm{L}^{-1}$ and $10 \mu \mathrm{g} \cdot \mathrm{L}^{-1}$ concentrations, the bioaccumulation process of A. japonicus does not conform to the two-box dynamic model, and the bioaccumulation equilibrium is not reached within $14 \mathrm{~d}$. Under concentration of $100 \mu \mathrm{g} \cdot \mathrm{L}^{-1}$, the bioaccumulation of 3-methylanthracene in A. japonicus increased with time, and the two - box dynamic model was used to fit, $\mathrm{K}_{1}=24.94, \mathrm{~K}_{2}=0.210, \mathrm{R}_{2}=0.923$ (95\% confidence interval). At low concentrations, the bioaccumulation of 3methylanthracene in A. japonicus did not obviously increase with time; In the case of high concentration of $10 \mu \mathrm{g} \cdot \mathrm{L}^{-1}$, the bioaccumulation of 3-methylanthracene in A. japonicus increased rapidly with the extension of exposure time, and even the enrichment coefficient BCF reached 154.6. At the same time, there was exponential correlation between the concentration of 3-methylphenanthrene and the bioaccumulation of 3-methylphenanthrene in A. japonicus, the correlation equations are $\mathrm{y}_{3 \mathrm{~d}}=6.492 \mathrm{e}^{1.2398 \mathrm{x}}$ $\left(\mathrm{R}_{3 \mathrm{~d}}^{2}=0.9448\right), \quad \mathrm{y}_{7 \mathrm{~d}}=5.4134 \mathrm{e}^{1.331 \mathrm{x}}\left(\mathrm{R}^{2} 7 \mathrm{~d}=0.8876\right)$ and $\mathrm{y}_{14 \mathrm{~d}}=5.5551 \mathrm{e}^{1.4745 \mathrm{x}}$ $\left(\mathrm{R}^{2}{ }_{14 \mathrm{~d}}=0.9446\right)$. Under the conditions of three concentrations, the content of 3-methylphenanthrene in $A$. japonicus increased rapidly, indicating that the bioaccumulation rate of $A$. japonicus was much higher than the metabolic rate.

\section{Effects of 3-methylphenanthrene on expression of CYP450 and p53 genes in A. japonicus}

The effect of 3-methylphenanthrene on expression of CYP450 gene in A. japonicus is shown in Figure 3. The results showed that, compared with the control group, 3-methylphenanthrene $\left(c \geq 5 \mu \mathrm{g} \cdot \mathrm{L}^{-1}\right)$ showed significant inhibitory effect on the expression of $C Y P 450$ gene of $A$. japonicus under certain concentration stress $(P<0.05)$. Compared with the control group, the overall relative expression of $C Y P 450$ gene in the treatment group was lower than that in the control group, and the relative expression of CYP450 
gene gradually increased with the increase of the concentration. The maximum expression of $C Y P 450$ gene in the $100 \mu \mathrm{g} \cdot \mathrm{L}^{-1}$ treatment group reached 0.56 at $14 \mathrm{~d}$, and the inhibition rate was $44 \%$ compared with the control group.

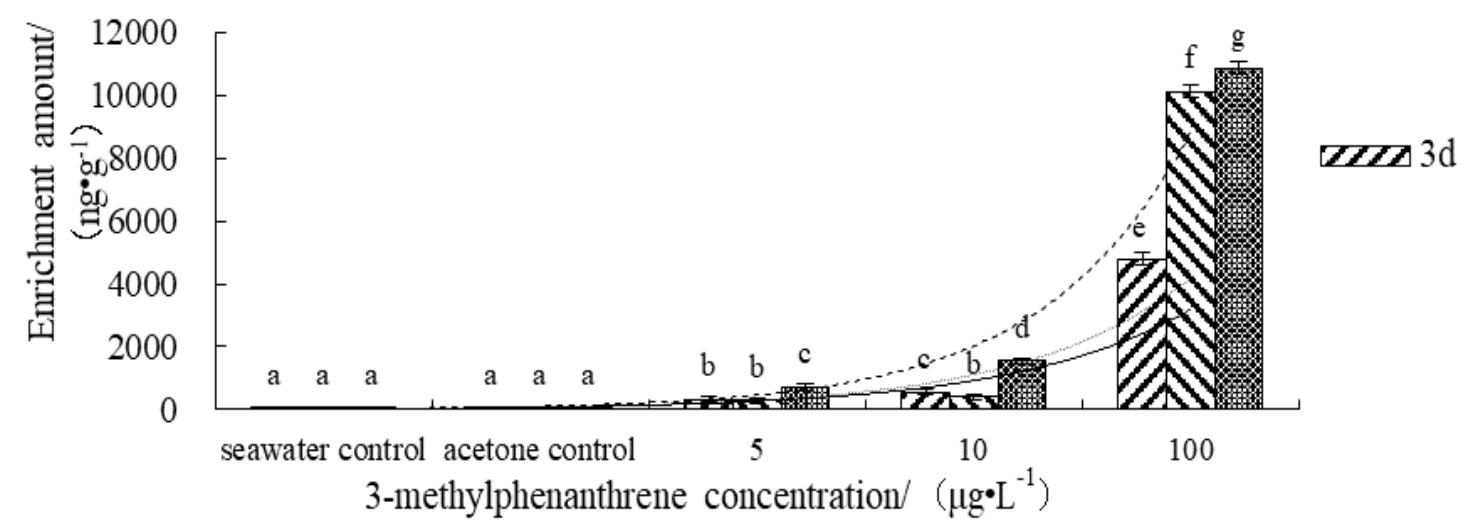

Figure 2. Bioaccumulation of dimethylanthracene by A. japonicus

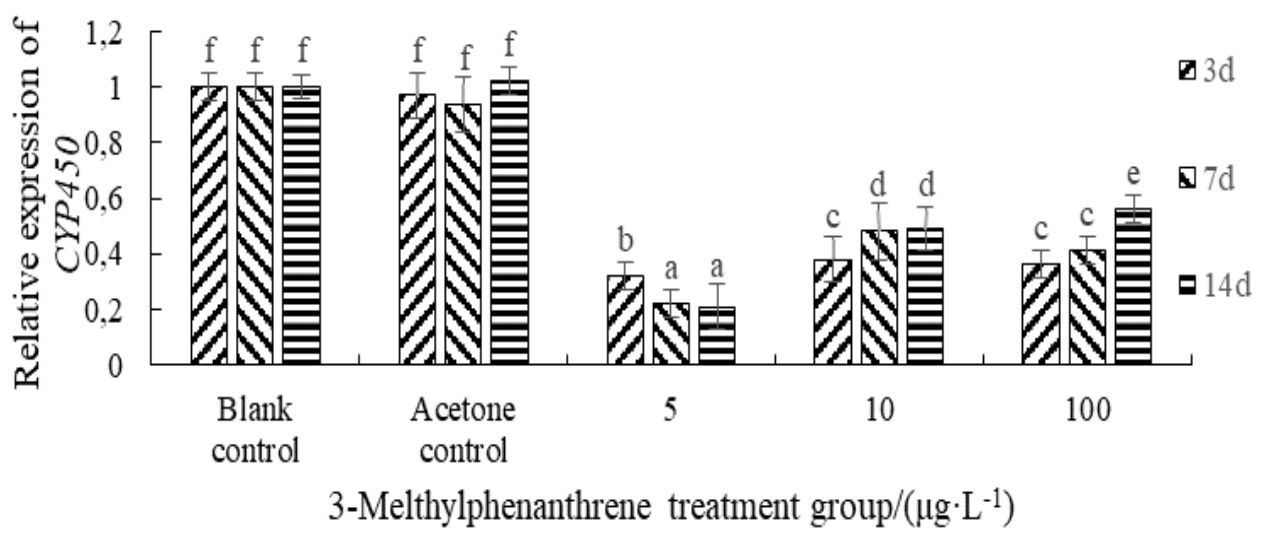

Figure 3. The effects of 3-methylphenanthrene on the CYP450 of A. japonicus

The effect of 3-methylphenanthrene on expression of p53 gene in A. japonicus is shown in Figure 4. At the early stress of 3-methylphenanthrene (3 d), all the 3-methylphenanthrene treatment groups showed significant inhibitory effect on the expression of $p 53$ gene $(P<0.05)$, and the inhibition effect decreased with the increase of stress concentration. At the middle stress of 3-methylphenanthrene ( $7 \mathrm{~d})$, with the increase of stress concentration, the relative expression of $p 53$ gene in A. japonicus showed a rule of increasing first and then decreasing, and it was at the lowest value of 0.137 when the stress concentration was $5 \mu \mathrm{g} \cdot \mathrm{L}^{-1}$, which the inhibition rate was $86.3 \%$ compared with the control group. At the later stress of 3-methylphenanthrene $(14 \mathrm{~d})$, with the increase of stress concentration, the relative expression of p53 gene in A. japonicus showed a gradually decreasing pattern, and reached the minimum value of 0.31 when the stress concentration was $100 \mu \mathrm{g} \cdot \mathrm{L}^{-1}$, which the inhibition rate was $69 \%$ compared with the control group. 


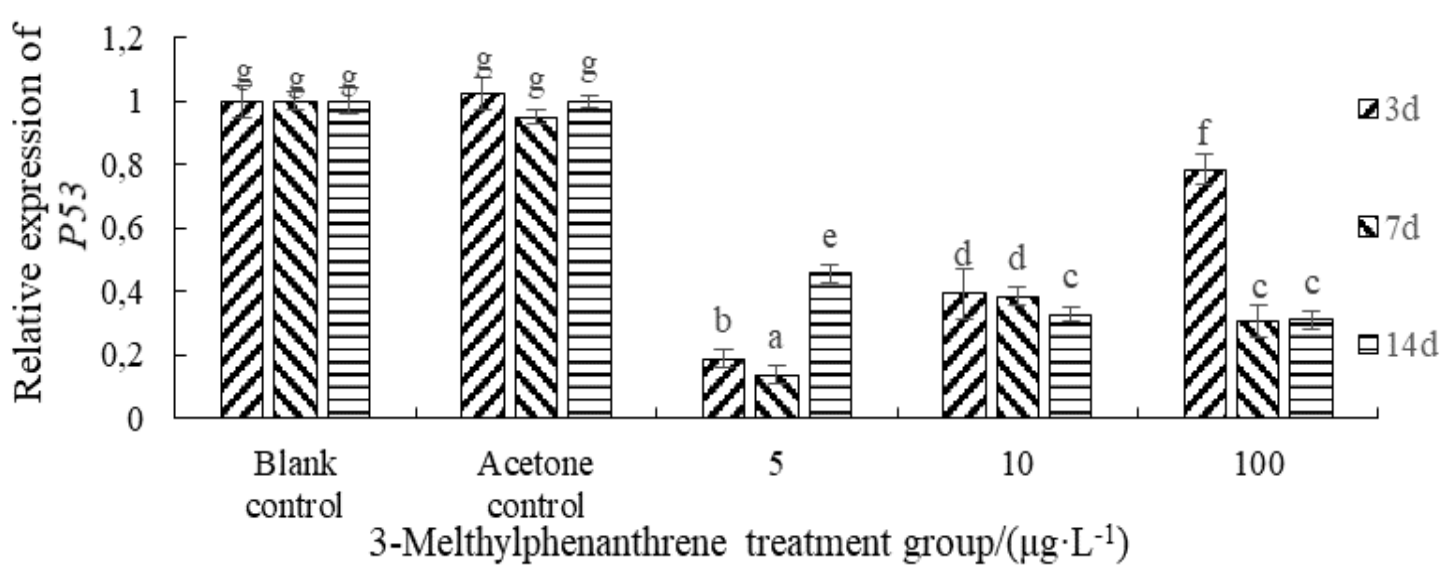

Figure 4. The effects of 3-methylphenanthrene on the p53 of A. japonicus

\section{Discussion}

3-methylphenanthrene can accelerate the accumulation of PAHs in Marine organisms, which is related to the high 1-octyl alcohol/water partition coefficient of PAHs (Hodson, 2017). Studies had found that PAHs can quickly dissolve in fat through respiration and surface penetration into aquatic organisms, thus causing harm to organisms (Li et al., 2016a). In addition to shellfish, other invertebrates have a certain role in the metabolism of PAHs (Yu et al., 2018; Mana et al., 2021). Therefore, the high concentration of 3 methylphenanthrene in the water environment can be degraded and absorbed by marine biodegradation, and eventually digested through the intestinal tract, which binds to the adipose tissue (Hodson, 2017). The results showed that the bioaccumulation amount and bioaccumulation rate of 3-methylphenanthrene increased with the increase of exposure concentration, and the bioaccumulation rate in high concentration increased rapidly with the increase of pollutant concentration. In addition, BCF decreases with the increase of pollutant concentration, which may be due to the combination of fat and organic pollutants is easier to reach the saturation state (Simning et al., 2019; Li et al., 2021).

The experimental results showed that with the extension of exposure time and the increase of exposure concentration, the survival rate of $A$. japonicus gastrula decreased gradually, and no individuals survived when the exposure concentrations were $100 \mu \mathrm{g} \cdot \mathrm{L}^{-1}$ (96 h) and $200 \mu \mathrm{g} \cdot \mathrm{L}^{-1}$ (72 $\mathrm{h}$ and $96 \mathrm{~h}$ ). Simning et al. (2019) reported that the cumulative mortality of embryo exposure of Cyprinodon variegatus significantly increased with the increase of HEWAF concentration $(6.25 \%-50 \%)$ under low salt conditions, and the results of the study were similar to the rule in this paper. Through exploratory analysis, PAHs have different effects on marine gastrulas and larvae (Simning et al., 2019): four kinds of PAHs can damage the tissues of A. japonicus, resulting in the death of the organism (Luo et al., 2015); Xylene reduces the hatching rate of Brachydanio rerio gastrula, leading to the death of gastrula or abnormal movement of developmental malformed larvae (Zhang et al., 2016). Therefore, it can be speculated that 3-methylphenanthrene is related to the toxic damage of $A$. japonicus gastrulas.

The expression of CYP450 and p53 genes showed an overall inhibitory effect under the stress of 3-methylphenanthrene, which was related to the different main functions and mechanisms of CYP450 and p53 genes in organisms. Different exogenous chemicals can cause oxidative stress, genotoxic stress and protein toxic stress after entering the 
organism, thereby activating the biological cellular detoxification metabolic system to maintain the relative stability of the environment inside organism (Duan et al., 2018). Marine invertebrates produce a large number of by-products -- reactive oxygen in the phase I metabolism of organic pollutants, and excessive reactive oxygen will lead to oxidative damage of organisms (Li et al., 2016b; Lister et al., 2017; Danielli et al., 2017; Duan et al., 2018). The CYP450 enzyme system can provide the basis for the second stage of glutathione transferase (GST) to transform the exogenous (Tang, 2019). In this study, the expression of CYP450 gene in A. japonicus was significantly inhibited under 3 -methylphenanthrene stress compared with the control group $(P<0.05)$ and the relative expression of $C Y P 450$ gene gradually increased with the increase of concentration, which showed a similar pattern to the effect of benzo[a]pyrene on gill tissue GSH activity of Mytilus coruscus (Tang, 2019). Therefore, it was speculated that the expression of CYP17A1 gene in A. japonicus was significantly increased after long treatment, because of it induces the detoxification and metabolism of cytochrome $P 450$ related system, and causes the production of excessive oxidative free radical ROS in the cell body.

P53 gene is the main attack site of chemical mutagenesis. After p53 gene mutation, it loses its regulatory effect on cell growth, apoptosis and DNA repair. And the complex network of regulation of cellular stress and cellular response is composed of its various regulatory factors and related genes (Li et al., 2019). In this study, the expression of p53 gene in A. japonicus was significantly inhibited under 3-methylphenanthrene compared with the control group $(P<0.05)$. However, in the same time period $(3 \mathrm{~d}$ and $7 \mathrm{~d})$, the relative expression level of $p 53$ gene increased with the increase of the concentration, which was due to the system in A. japonicus did not respond in time at the beginning and so as to inhibit the expression of p53 gene in A. japonicus. When the stress concentration increased, the detoxification and metabolism process of cytochrome related system was induced, and oxidative stress occurred, and the expression level of p53 increased significantly (Liu et al., 2015). It has been reported that nano-silica coated with manganese oxide can induce the increase of $p 53$ gene expression in He La cells and L929 cells (Yu et al., 2015). Therefore, it is speculated that 3-methylphenanthrene has no strong toxic effect on A. japonicus under low concentration $\left(\mathrm{c} \leq 100 \mu \mathrm{g} \cdot \mathrm{L}^{-1}\right)$ and short time $(\mathrm{t} \leq 14 \mathrm{~d})$ stress.

\section{Conclusion}

In this study, high concentration of 3-methylphenanthrene inhibited the survival of A. japonicus gastrula and inhibited the metabolism of 3-methylphenanthrene in A. japonicus, resulting in the bioaccumulation of 3-methylphenanthrene. The expression of CYP450 and p53 genes in A. japonicus gastrula was significantly inhibited by 3-methylphenanthophane, thus inhibiting the metabolic effect of pollutants and losing the regulatory effect on cell growth, apoptosis and DNA repair. Changes in the metabolic mechanism and regulatory mechanism of marine organisms may lead to the death of marine organisms. Therefore, the relevant marine departments should prohibit the discharge of industrial wastewater into the sea and timely deal with marine oil spills, strengthen the monitoring of PAHs in the marine environment and the management of the total amount of marine pollutants discharged, which will provide a good living environment and solve the major problems of aquaculture. 
Acknowledgments. We acknowledge the Key Projects of the National Science and Technology Pillar Program (No:201305002), Open Fund of the Key Laboratory of Marine Oil Spil Identification and Damage Assessment Technology, State Oceanic Administration (No.201309, 201809), the Key Laboratory of Coastal Ecological Environment, State Oceanic Administration (No.201013), Local Projects of the Department of Education of Liaoning Province (DL201804) and The Major and Special Program on Science and Technology Projects in Dalian City (2020ZD23SN009) for supporting this research and Dalian Ocean University for providing facilities.

\section{REFERENCES}

[1] Bo, K. (2017): Identification and purchasing techniques of sea cucumber. - China Anticounterfeiting Report 6: 124-125.

[2] Danielli, N. M., Trevisan, R., Mello, D. F., Fischer, K., Deconto, V. S., Daiane, D. S. A., Bianchini, A., Bainy, A. C. D., Dafre, A. L. (2017): Upregulating Nrf2-dependent antioxidant defenses in pacific oysters, Crassostrea gigas: Investigating the Nrf2/Keap1 pathway in bivalves. - Comparative Biochemistry \& Physiology Part C Toxicology \& Pharmacology 195: 16-26.

[3] Duan, M., Xiong, D., Bai, X., Gao, Y., Xiong, Y., Gao, X., Ding, G. H. (2018): Transgenerational effects of heavy fuel oil on the sea urchin Strongylocentrotus intermedius considering oxidative stress biomarkers. - Marine Environmental Research 141: 138-147.

[4] Guan, X. Y., Wang, B., Dong, Y., Li, S. Q., Gao, S., Liu, W. D., Zhou, Z. C. (2016): Effects of Xylene, Anthracene, and Benzo[a]pyrene on Enzymatic Activities of SOD and CAT in the Japanese Scallop (Mizuhopecten yessoensis) Serums. - Journal of Ecotoxicology 11(1): 289-294.

[5] Guo, R. M., Pan, L. Q., Lin, P. F., Zheng, L. (2017): The detoxification responses, damage effects and bioaccumulation in the scallop Chlamys farreri exposed to single and mixtures of benzo[a]pyrene and chrysene. - Comparative Biochemistry and Physiology Part C 191: 36-51.

[6] Hodson, P. V. (2017): The Toxicity to Fish Embryos of PAH in Crude and Refined Oils. Archives of Environmental Contamination and Toxicology 73(1): 12-18.

[7] Honda, M., Suzuki, N. (2020): Toxicities of Polycyclic Aromatic Hydrocarbons for Aquatic Animals. - International Journal of Environmental Research and Public Health 17(4): 1-23.

[8] Khazaali, A., Kunzmann, A., Bastami, K. D., Baniamam, M. (2016): Baseline of polycyclic aromatic hydrocarbons in the surface sediment and sea cucumbers (Holothuria leucospilota and Stichopus hermanni) in the northern parts of Persian Gulf. - Marine Pollution Bulletin 110(1): 539-545.

[9] Li, C., Zhou, S., Ren, Y. C., Jiang, S. H., Xia, B., Dong, X. Y. (2016a): Toxic effects in juvenile sea cucumber Apostichopus japonicas (Selenka) exposure to benzo[a]pyrene. Fish and Shellfish Immunology 59: 375-381.

[10] Li, L., Jiang, M., Shen, X. (2016b): Variability in antioxidant/detoxification enzymes of Sinonovacula constricta exposed to benzo[a]pyrene and phenanthrene. - Marine Pollution Bulletin 109(1): 507-511.

[11] Li, X., Wei, H. F., Liu, C. F., Song, X., Zhao, X. Y., Zhao, Y. M., Xia, N., Huo, Y. J. (2019): Effects of 2 Kinds of alkyl-PAHs on the Expression of CYP450 and P53 Genes of Apostichopus japonicus. - Journal of Ecotoxicology 14(1): 83-89.

[12] Li, X. S., Wang, C. Y., Li, N., Gao, Y. L., Ju, Z. L., Liao, G. X., Xiong, D. Q. (2021): Combined Effects of Elevated Temperature and Crude Oil Pollution on Oxidative Stress and Apoptosis in Sea Cucumber (Apostichopus japonicus, Selenka). - International Journal of Environmental Research and Public Health 18(2): 801-801. 
[13] Lister, K. N., Lamare, M. D., Burritt, D. J. (2017): Maternal antioxidant provisioning mitigates pollutant-induced oxidative damage in embryos of the temperate sea urchin evechinus chloroticus. - Scientific Reports 7(1): 1954.

[14] Liu, L., Zhao, Q. F., Zhu, S. Q., Xu, F. (2015): Oxidative damage of zinc oxide nanoparticles to zebrafish intestine. - Acta Aquatica Sinica 39(11): 1702-1711.

[15] Liu, S., Su, T. T., Liu, C. F., Wei, H. F., Zhao, X. Y., Song, X. (2020): Effects of 3 Kinds of PAHs on the Expression of CYP17Al Genes of Strongylocentrotus intermedius. Journal of Ecotoxicology 15(5): 345-351.

[16] Luo, Y. M., Xu, W. D., Li, D. H., Chen, D. F., Wang, X. Y. (2015): Acute Toxicity of Propylene Oxide, Acrylic Acid and Isoprene to Juvenile Sea Cucumber Apostichopus japonicus. - Fisheries Science 34(7): 444-447.

[17] Mana, I., Jun, S., Takeshi, H., Tohru, M., Katsutoshi, I. (2021): Immune toxicity of phenanthrene and its combined effects of white spot syndrome virus on the survival of kuruma shrimp (Penaeus Japonicus). - Ecotoxicology and Environmental Safety 208.

[18] Mohsen, M., Zhang, L. B., Sun, L. N., Lin, C. G., Wang, Q., Yang, H. S. (2020): Microplastic fibers transfer from the water to the internal fluid of the sea cucumber Apostichopus japonicus. - Environmental Pollution 257: 113606.

[19] Mohsen, M., Zhang, L. B., Sun, L. N., Lin, C. G., Wang, Q., Liu, S. L., Sun, J. C., Yang, H. S. (2021): Effect of chronic exposure to microplastic fibre ingestion in the sea cucumber Apostichopus japonicus. - Ecotoxicology and Environmental Safety 209: 111794.

[20] Simning, D., Sepulveda, M., De, G. S., Bosker, T., Griffitt, R. J. (2019): The combined effects of salinity, hypoxia, and oil exposure on survival and gene expression in developing sheepshead minnows, Cyprinodon variegatus. - Aquatic Toxicology (Amsterdam, Netherlands) 214: 105234.

[21] Tang, Z. R. (2019): Study on antioxidant reaction and Nrf2 gene expression of mussel with single and mixed cadmium and benzo[a]pyrene exposure. - Zhejiang Ocean University.

[22] Wang, J., Ren, T. J., Wang, F. Q., Han, Y. Z., Liao, M. L., Jiang, Z. Q., Liu, H. Y. (2016): Effects of dietary cadmium on growth, antioxidants and bioaccumulation of sea cucumber (Apostichopus japonicus) and influence of dietary vitamin C supplementation. Ecotoxicology and Environmental Safety 129: 145-153.

[23] Xu, Y. Q., Zhong, Y. W., Han, J. H., Qin, Z. B., Li, W. F., Ding, Z. K. (2018): Effect and mechanism of phenanthrene on the reproduction, development, and growth of aquatic animal. - Feed Industry 39(16): 61-64.

[24] Yu, C., Zhou, Z., Wang, J., Sun, J., Liu, W., Sun, Y. N., Kong, B., Yang, H., Yang, S. P. (2015): In depth analysis of apoptosis induced by silica coated manganese oxide nanoparticles in vitro. - Journal of Hazardous Materials 283: 519-528.

[25] Yu, N., Ding, Q. Q., Li, E. C., Qin, J. G., Chen, L. Q., Wang, X. D. (2018): Growth, energy metabolism and transcriptomic responses in Chinese mitten crab (Eriocheir sinensis) to benzo[a]pyrene (BaP) toxicity. - Aquatic Toxicology 203: 150-158.

[26] Zhang, P., Xing, X. L., Sun, J. X., Zhao, W. (2016): Research progress on the pollution and toxicity of heavy metals on sea cucumber. - Marine Environmental Science 35(1): 149154.

[27] Zhao, G. H., Zhao, W. F., Han, L. S., Ding, J., Chang, Y. Q. (2020): Metabolomics analysis of sea cucumber (Apostichopus japonicus) in different geographical origins using UPLCQ-TOF/MS. - Food Chemistry 333: 127453. 